\title{
ROMANCES FAMILIARES E HERANÇAS PSICOSSOCIAIS
}

\section{Teresa Cristina Othenio Cordeiro Carreteiro}

Universidade Federal Fluminense /NUPESV-UFF

\section{Ana de Santa Cecília Massa}

Fundação Dom Cabral/ENSP-Fiocruz /NUPESV-UFF

\section{Luciana da Silva Rodriguez}

Faculdade Machado de Assis /NUPESV-UFF
Recebido em: 06/10/2019

$1^{\text {a }}$ revisão em: 05/12/2019

Aceito em: 05/04/2020

\section{RESUMO}

Este artigo examina a influência da família e dos efeitos das heranças psicossociais na trajetória do sujeito. A psicossociologia - e suas interseções com a psicanálise e a sociologia - é discutida como referencial teórico-metodológico que possibilita explorar essa problemática. O estudo "Romance Familiar e a Trajetória Social", que se apoia no método de história de vida em grupo, fundamenta a discussão, que é seguida pela análise do relato de uma participante de um grupo intitulado "Mudanças de vida: entre perdas e vínculos", que nos fornece elementos para discutir a transmissão sociopsíquica entre gerações e seus traços nas produções subjetivas do indivíduo.

Palavras-chave: herança familiar; psicossociologia; história de vida. 


\section{FAMILY ROMANCES AND PSYCHOSOCIAL HERITAGE}

This article examines the influence of the family and the effects of the psychosocial heritage in the trajectory of the subject. Psycosociology, and its intersections with psychoanalysis and sociology, is discussed as theoreticalmethodological referential that allows us to explore such issue. We will present the device "Family Romances and psychosocial heritage", that utilizes the history of life in groups. We will analyze as furthers as the report of a participant of a group entitled "Life changes: between losses and bonds", which allows us to analyze the socio-psychic transmission among generations and their traits in the subjective productions of the individual.

Keywords: family heritage; psycosociology; history of life.

\section{ROMANCES FAMILIARES Y HERENCIAS PSICOSSOCIALES}

\section{RESUMEN}

Este artículo examina la influencia de la familia y los efectos de las herencias psicosociales en la trayectoria de un individuo. La psicosociología, y sus intersecciones con el psicoanálisis y la sociología, es discutida como un marco teórico-metodológico que permite explorar tal problema. Presentamos, entonces, un dispositivo grupal llamado "Romance familiar y trayectoria social" apoyado en el método de historia de vida. Seguimos con un análisis de un participante en un grupo titulado "Cambios en la vida: entre restricciones y vínculos", que nos proporcionan elementos para discutir la transmisión psicológica entre las generaciones y sus rasgos en las producciones subjetivas del individuo

Palabras clave: herencia familiar; psicosociología; historia de vida. 


\section{INTRODUÇÃO}

Discutir as imbricações da herança familiar na produção subjetiva e trajetória social do sujeito implica esclarecer as bases que compõem os diferentes fios dessa trama. Apoiadas na psicossociologia (Barus-Michel, Enriquez, \& Levy, 2005; Carreteiro, 2001a; 2005), entendemos que toda investigação deve articular as dimensões psíquicas, sociais e políticas de seus objetos de estudo. Para essa abordagem, o sujeito é duplamente constituído: por um lado pelos elementos intrapsíquicos singulares; por outro, por sua inscrição no universo familiar e social. Com isso, as reciprocidades entre o psíquico e o social, o individual e o coletivo são fundamentais, e postula-se a indissociabilidade de ambos.

Não existe sujeito fora do social, e a psicossociologia se interessa pelas situações reais das quais todo indivíduo participa. São situações que existem com ele e fora dele, que o influenciam e que por ele são influenciadas. (Lhuilier, 2011). Gaulejac (2001a) se utiliza da imagem das Matrioshkas - conjunto de bonecas em tamanhos crescentes que se encaixam umas dentro das outras - como metáfora para se referir ao entrelaçamento dos diversos aspectos de uma história. "Tal como uma boneca russa, a história individual está aninhada em uma história familiar, ela própria inserida em uma história social. Cada um se inscreve nessa rede que estabelece o seu lugar, a sua identidade. Nesse sentido, o homem é história." [grifo original do autor] (Gaulejac, 2014, p. 24).

É nessa direção que propomos discutir a influência da família e dos efeitos das heranças psicossociais na trajetória do sujeito. A família tem um papel fundamental no processo humano de desenvolvimento e socialização. Discutir a transmissão sociopsíquico-geracional é pensar nas heranças familiares, naquilo que foi herdado pelas gerações subsequentes. Corroborando com essa ideia, Féres-Carneiro e Magalhães (2005) afirmam que a "transmissão psíquica [é] uma chave de conhecimento para pensar a dinâmica psíquica intersubjetiva familiar e conjugal e suas consequências no processo de subjetivação." (p. 24).

A criança, mesmo antes de nascer, já está presente na fala dos pais e ocupa um lugar em seus desejos. Inscreve-se em uma ordem simbólica e se insere na economia libidinal familiar (Oliveira, \& Darriba, 2005). No entanto, a construção do Eu não se dá apenas no "jogo do desejo e do interdito" do triângulo formado no Complexo de Édipo. Os lugares sociais ocupados na sociedade são, igualmente, suportes à sua constituição, "toda relação com o outro é, de imediato e simultaneamente, uma relação social" (Gaulejac, 2001b, p. 109).

As articulações entre o campo familiar e o campo social são exploradas pelo dispositivo "Romance Familiar e Trajetória Social", suporte teórico-metodológico que tem Vincent de Gaulejac como um de seus precursores. Esse dispositivo propõe um trabalho de desenvolvimento pessoal que põe em evidência as imbricações das dimensões psicossociais nas trajetórias individuais com base na história de vida trabalhada em grupo. Ele pode ter, como veremos, diferentes 
focos temáticos, entre os quais aquele que evocaremos neste artigo, ou seja, o grupo "Mudanças de vida: entre perdas e vínculos".

Discutiremos essas problemáticas com base no relato de uma participante do grupo supracitado, a quem chamaremos de Germana. Apoiadas na Resolução 510, de 7 de abril de 2016, do Conselho Nacional de Saúde, esse relato, resultado de atuação profissional, respeita os aspectos legais de sigilo, resguardando a privacidade da participante, sem identificá-la. Vamos nos restringir a apresentar alguns elementos específicos que nos ajudem na análise teórico-metodológica desse dispositivo.

\section{HERANÇA FAMILIAR E TRANSMISSÃO PSICOSSOCIAL}

Para a psicossociologia, cada trajetória se produz na multideterminação das dimensões psíquicas e sociais, o que inclui os aspectos familiares, culturais, econômicos, políticos e históricos. A psicossociologia pressupõe, então, a interdisciplinaridade. Optamos por fazer dialogar a psicanálise e a sociologia por representarem arcabouços teóricos centrais no que concerne à questão da transmissão psicossocial das heranças familiares. Entendemos, porém, que outros saberes e disciplinas podem ser mobilizados, compondo nossa caixa de ferramentas, de forma a apreender melhor a singularidade e a complexidade do objeto estudado.

No que concerne à psicanálise, a questão da família ocupa lugar central, perpassando toda a obra freudiana, mesmo que a discussão sobre o tema não tenha sido sistematizada. Ao longo dos seus escritos, principalmente pela análise dos seus casos clínicos, Freud fez apontamentos importantes destacando a relação dos seus pacientes com suas famílias. Demonstrou em inúmeras situações $(1905,1909,1913,1914,1921)$ o entrelaçamento dos sintomas de seus pacientes com os sintomas familiares, enfatizando a importância dos vínculos afetivos. Segundo Freud (1921), a intersubjetividade participa da constituição psíquica do sujeito, e as identificações são a base narcísica do sentimento de pertença grupal-comunitário. Essa identificação está no centro do processo de transmissão entre as gerações, sustentando valores, crenças e diversos saberes que asseguram a continuidade grupal, cultural.

O primeiro laço afetivo se estabelece pela identificação com os pais. Eles serão os primeiros suportes idealizados da criança, que ambiciona tornar seu ego semelhante ao seu ideal. A experiência de filiação estabelece um laço íntimo com o ideal do ego, cuja formação mantém uma tensão entre o individual e o social. O desejo da criança de ser como seus pais é seu primeiro passo na direção do outro, pois, além dos pais, o sujeito vai designar, ao longo da vida, outros modelos que o conduzirão a realizações pessoais no seu ambiente social. No entanto, no texto "Romances Familiares", Freud (1909) afirma que o encontro com outros adultos, que funcionarão como modelos sociais para a criança, são responsáveis por um processo de progressiva diferenciação dela em relação aos pais. Há um momento no qual as qualidades que antes eram atribuídas aos 
progenitores passam pela crítica infantil, e a criança chega a duvidar de que eles sejam seus verdadeiros pais. Nessa fase, surge também a comparação entre posições sociais familiares com linhagens de prestígio. As crianças negam a realidade dos pais e fantasiam ser filhos adotivos e originários de uma categoria social prestigiosa e superior, situação que Freud denomina "romances imaginativos". Se na época os personagens desses romances eram inspirados em figuras reais e aristocráticas, hoje, o que pode surgir como paisagem social são os personagens de novelas televisivas e pessoas com grande poder de consumo que exibem suas imagens nas mídias e redes sociais. A atualidade do texto freudiano para nosso propósito é construir a psicodinâmica na articulação com os aspectos sociais.

Desse modo, a identificação não remete exclusivamente ao imago parental, ela está sempre inscrita no social. Toda identificação traz em seu rastro traços sociais, elementos de práticas sociais. Os pais não são unicamente progenitores, eles exercem diversos papéis: são profissionais ou não, figuras que têm ou não visibilidade, pessoas que têm ou não uma posição política militante.

Essas ideias nos remetem às teorizações de Bourdieu (1979) ao se referir à dimensão social da herança familiar, notadamente da transmissão do capital cultural, que se manifesta nas escolhas da vida cotidiana - como vestuários, alimentação, decoração da moradia - e inscreve a família dentro do campo social. Segundo o sociólogo, a herança material é ao mesmo tempo uma herança cultural. Os bens de família são, para as classes abastadas, uma forma de garantir a continuidade da linhagem no tempo, preservando sua identidade social e transmitindo "valores, virtudes e competências". O capital cultural herdado determina a intimidade com certos objetos, cheiros, alimentos, qualificando gostos e preferências no seio de um universo social. É nesse sentido que Bourdieu (1979) ressalta o aspecto social do pertencimento ao grupo familiar, cuja posição no campo social determina práticas expressas pelos habitus que evidenciam a distinção entre classes sociais e tensionam as relações de dominação entre elas. Desse modo, Bourdieu forja o conceito de habitus, um esquema de classificação incorporado em uma cultura de classe social, gerador de práticas sociais que têm suas configurações específicas lidando com os diversos campos da vida social. O autor reivindica, assim, a necessidade de uma "psicanálise social" (p. 84) que buscaria apreender a lógica das relações sociais objetivadas nas coisas e nas pessoas que refletem a transmissão da dimensão social da herança familiar.

O principal mecanismo envolvido nesse processo de transmissão entre gerações, como dissemos, é a identificação. Por meio dela, o sujeito ampara a continuidade narcísica. Apoiados em Bourdieu, acrescentamos que as identificações trazem também consigo elementos associados ao habitus, que devem ser integrados na compreensão da transmissão. Assim, inscrevemos os aspectos sociais às transmissões psíquicas. 
É essencial, portanto, pensar as questões psicossociais vinculadas à filiação. Para Gaulejac (2014), as contradições sociais que atravessam as histórias familiares estão na origem dos conflitos psíquicos:

A sociedade e a família canalizam os desejos, impõem proibições, propõem ideais coletivos, modelos de identificação, sistemas de valores e normas. Elementos que influenciam a psicologia consciente e inconsciente de seus membros. Inversamente, os indivíduos contribuem para produzir sistemas sociais e familiares que respondam às suas aspirações e que estejam de acordo com sua personalidade. É, pois, a combinação desses diferentes registros e a análise de suas articulações que é verdadeiramente explicativa. (Gaulejac, 2014, p. 9).

Gaulejac (2014), tecendo diálogo entre as contribuições de Freud e do sociólogo Bourdieu, atesta que "quer rejeitemos quer aceitemos nosso passado, ele cola à nossa pele, ele é nossa pele. Quanto mais o indivíduo tende a ignorar que ele é produto de uma história, mais se torna seu prisioneiro" (p. 34).

Sendo assim, quando nos propomos a escutar a dinâmica relacional familiar, podemos compreender melhor como os vínculos afetivos foram construídos e também como estão sustentadas as lealdades, as crenças e os mitos (Scherer More, \& Coradini, 2017). Todos esses componentes se articulam de maneira integrada e, por vezes, invisível para a maioria dos membros.

De forma geral, a psicanálise nos mostra que o aparelho psíquico tem uma lógica interna de funcionamento própria, mas Gaulejac (2014) nos lembra que fenômenos sociais significativos aos sujeitos, com repercussões psíquicas importantes, podem provocar conflitos de identidade. E uma das originalidades do dispositivo "Romance familiar e trajetória social" é justamente esta: a de vincular, em permanência, a experiência subjetiva do sujeito com a realidade social. Desse modo, a construção subjetiva vai depender da arte de cada sujeito de se construir em permanência por meio dos diversos eixos que o atravessam.

\section{TRABALHO SOBRE, HISTÓRIA DE VIDA: HERANÇA FAMILIAR E TRAJETÓRIA SOCIAL}

A perspectiva teórica metodológica "Romance Familiar e Trajetória Social" nasce da psicossociologia e da sociologia clínica. Foi inicialmente elaborada pelos psicossociólogos Vincent de Gaulejac, Michel Bonetti e Jean Fraisse na década de 1970, na França. O principal objetivo era o de explorar, como dissemos, a interdependência entre fenômenos sociais e desenvolvimento psíquico, partindo de uma perspectiva clínica. Foi criado, assim, um dispositivo para o desenvolvimento pessoal, que propõe a reflexão e a implicação baseadas em duas dimensões da construção subjetiva: a esfera familiar e a trajetória social (Carreteiro, 2001b). O uso dessa ferramenta teórico-metodológica possibilita 
analisar os projetos parentais, suas contradições, a herança sociofamiliar que o indivíduo recebe de seus ascendentes, as mensagens ambíguas a eles endereçadas, pondo em evidência as formas de influência dessas duas dimensões. Esse dispositivo ganha força no contexto científico francês até então marcado por trabalhos exclusivamente estatísticos e foi se expandindo progressivamente em universidades e em institutos de formação profissional na Bélgica, no Quebec, na Itália, na Grécia, no México, na Argentina, no Chile e também no Brasil.

De forma geral, esses grupos são compostos de oito a quinze participantes, que se reúnem durante três ou quatro dias de trabalho consecutivos em função de uma determinada temática. Para cada um desses grupos são usados suportes metodológicos específicos, que funcionam como estruturas mediadoras para que se alcancem os objetivos do grupo. Destacamos que os grupos dedicam constante atenção ao eixo da trajetória social e ao da genealogia sociofamiliar, explorando esses dois aspectos em cada temática. Nesse dispositivo, podem ser utilizados recursos que favoreçam a expressão do projeto parental, da árvore genealógica e da trajetória individual. Existe sempre atenção ao eixo familiar e intergeracional, ao eixo pessoal e à articulação entre ambos. Assim, diferentes registros da existência são mobilizados, como emoções, fantasias, contexto social e familiar e também os acontecimentos históricos e sua incidência sobre a vida das famílias e dos indivíduos.

Aos coordenadores cabe um olhar que possa articular a dinâmica grupal e os dados da realidade histórica, social e psicofamiliar que intrevêm na produção do sujeito. Além disso, devem estar atentos aos sentidos das experiências que emergem no grupo, nas zonas obscuras, nos segredos, nas transmissões, nas interdições sociopsíquicas. Eles buscam estabelecer pontes entre os fenômenos sociais e coletivos e a experiência narrada. Os coordenadores solicitam que cada pessoa esteja atenta ao que deseja ou não comunicar, assim como ao que imagina que o outro possa ou não ouvir. Eles encorajam ainda a função expressiva e reflexiva do grupo. No entanto, os habitus (Corcuff, 1993) vinculados ao pertencimento a classes sociais estão tão incrustados e naturalizados nos sujeitos que podem dificultar essas atitudes. Ao se questionar sobre os valores sociais, ao se analisar os conflitos gerados nas trajetórias individuais e sociais e ao se estar atento às repercussões que eles possam ter no interior dos grupos, é possível que surjam efeitos de mudança. Isso permite aos participantes descentrar o olhar habitual de forma a torná-los capazes de compreender fenômenos sociais.

Trata-se de um trabalho sobre as narrativas de vida em grupo, em que os participantes compartilham experiências que se entrecruzam, alternando fases de trabalho pessoal, de análise e de produção coletiva de hipóteses sobre as situações narradas. $O$ trabalho em grupo apresenta-se como suporte para que cada um, individualmente e com apoio do coletivo, reflita e possa (re)significar situações vividas e experienciadas. Não podemos negligenciar, nesse processo de 
construção das narrativas, as condições concretas de sua emergência, o campo intersubjetivo. Todo sujeito fará apelo à sua experiência e à sua memória na articulação com as situações presentes por ocasião da narração.

Destacamos que um dos aspectos dessa metodologia é a de pôr em evidência a associação entre a realidade objetiva dos fatos sociais e a experiência subjetiva de cada sujeito, ou seja, a forma como cada um percebe, produz significados e sentidos singulares para os acontecimentos da vida. As análises desses dispositivos nos mostram como, em cada história de vida, que é ao mesmo tempo individual e social, existe uma forte tensão entre o sujeito produzido pela história e o sujeito que deseja ser reconhecido como construtor de sua história.

Todo sujeito é herdeiro de uma história que o antecede e que exerce impacto sobre sua vida. Tanto a esfera familiar como a trajetória social do indivíduo deixam marcas na sua construção subjetiva e de seus projetos. Os desejos dos pais para os filhos, o pertencimento a uma determinada classe social, os valores e as crenças transmitidos, os grupos de pertencimento, todas essas experiências produzem incidências no seu percurso.

\section{GRUPO DE HISTÓRIA DE VIDA: “MUDANÇAS DE VIDA - ENTRE PERDAS E VÍNCULOS"}

O dispositivo "Romance familiar e trajetória social" pode se centrar em vários temas, como já dissemos anteriormente. Neste momento, enfocaremos aquele que trata de "Mudanças de vida: entre perdas e vínculos" (Les tournants de la vie, entre pertes et attachements). Ele constitui uma proposta de formação continuada pelo Instituto Internacional de Sociologia Clínica (IISC), na França, sob coordenação de duas das autoras deste artigo. Esse dispositivo se centra na noção de "acontecimento", podendo remeter a eventos biográficos exógenos, como mudanças na estrutura familiar, mortes, guerra, exílio, momentos históricos, mudanças associadas ao trabalho, desemprego, entre outros.

Esses "acontecimentos", por terem grande impacto na vida das pessoas, são considerados pelo sociólogo Michel Legrand (1993) como categoria biográfica. Em uma história de vida, ela representa um momento de mudança, um momento de ruptura (Figueiredo, 1993). Nessa perspectiva, o acontecimento produz disjunções na trama das representações e das rotinas. Ele cria esgarçamento no tecido da realidade como uma pré-figuração da morte (Heideggard, como citado em Figueiredo, 1993, p. 46). Esse estado abre possibilidades de mudanças. Há, portanto, uma potência disruptiva, cabendo ao sujeito que o vive, na relação com o contexto que o cerca (familiar, institucional, político, econômico etc.), criar formas de enfrentar e recriar dimensões de existência, a partir do seu advento.

Todo acontecimento-ruptura cria uma inflexão temporal, rompendo com a ilusória ideia de linearidade, na medida em que separa o tempo entre o "antes e o depois". Ele também traz um esgarçamento de sentido para aquele que o experiencia. O sujeito não consegue mais se representar como antes. Toda a 
atividade de atribuição de sentido encontra-se anestesiada, congelada, "vazia" (Figueiredo, 1993, p. 47). Durante o acontecimento, há rompimento radical dos recursos simbólicos, uma impossibilidade de buscar novas formas de significação. Consideramos que poder recompor os recursos simbólicos depende dos apoios contextuais e da capacidade do sujeito de poder usá-los para realizar um trabalho de luto e de reconstrução. O luto requer sempre um remanejamento psíquico e da realidade. É com base nesse trabalho que a temporalidade poderá começar a ser re-tecida, e o futuro voltar a encontrar formas de se representar.

É nessa direção que este grupo convida os sujeitos participantes a explorar a singularidade com que cada um atravessa os momentos de mudanças da vida.

\section{GERMANA: ENTRE ELABORAÇÃO E RECONSTRUÇÃO DA HERANÇA FAMILIAR}

Apresentamos um recorte da narração e da participação de Germana no grupo "Mudanças de vida: entre perdas e vínculos". Esse grupo foi formado por oito participantes. Os encontros se deram durante três dias consecutivos, no período da manhã e da tarde, contabilizando aproximadamente 6 horas diárias de atividades. Para esse dispositivo é essencial que o trabalho ocorra em dias seguidos, o que possibilita aprofundar a reflexão por meio da implicação de cada participante em relação ao tema abordado e o distanciamento em relação à trajetória pessoal. Assim, torna-se possível revisitar uma mesma questão ao longo dos dias de trabalho e do processo do grupo. Escolhemos discutir o caso Germana em razão de seu relato pôr em evidência a influência da sua herança sociopsíquica, sua vida pessoal, familiar, amorosa e profissional, como veremos adiante.

Germana tem 56 anos, nasceu em uma cidade do centro-oeste da França. Até seus 40 anos, cuidava exclusivamente dos cinco filhos, não exercia nenhuma atividade profissional. Hoje ela trabalha num serviço de proteção infantil da primeira infância. Ela auxilia os pais a entender o que acontece quando "as coisas dão errado com filhos". Em seu trabalho, ela é "confrontada com maus tratos de crianças". Considera ser seu papel acompanhar as pessoas "para que elas possam seguir em frente". Essas expressões foram utilizadas por ela mesma em sua apresentação para o grupo, atribuindo a sua participação nesse espaço como uma forma de ter mais recursos teórico-metodológicos para ajudá-la em seu trabalho.

Germana tem uma aparência bastante jovem, fala com uma voz suave, sempre exibindo um sorriso. No decorrer do trabalho em grupo, ela revela a força de uma mulher que teve cinco filhos e que, há quatorze anos, separou-se do marido para "viver sua vida". Ela narra que a separação faz parte de um passado "resolvido". Acontecimentos da nova vida, novos amores e separações já ocorreram, mas ainda há um passado mais antigo para revisitar. 
O grupo inicia com um aquecimento utilizando um recurso musical, por meio do qual foi proposto um trabalho de expressão corporal. Solicitou-se a cada um, depois de certo tempo caminhando pela sala, que escolhesse uma posição, como uma escultura a ser encenada com o seu próprio corpo, que tivesse relação com a temática do grupo. Germana faz a escultura de alguém dobrado sobre si mesmo. Ela abraça os joelhos com os braços e inclina a cabeça sobre eles. Ela intitula essa posição de solidão. Associa esse sentimento ao nascimento de sua irmãzinha, quando tinha quinze meses de idade. Nesse momento, foi separada de seus pais e irmão e levada a residir temporariamente em um abrigo para crianças pequenas. Seu irmão mais velho foi entregue a uma tia, que, na época, poderia se ocupar de apenas uma criança. Os pais consideravam que só seria possível cuidar do recém-nascido. Seu pai costumava visitá-la, porém, no momento de encontrálo, ela sempre "berrava". Esse comportamento persistiu, de forma que a instituição solicitou ao pai que não voltasse mais a vê-la.

Sua mãe relatava que, ao retornar à família, ela se tornou uma criança difícil. Ela diz: "eu era insuportável". A palavra "insuportável" passa a ser um significante de forte carga afetiva. É com essa afirmação que Germana faz reviver a palavra de sua mãe que será repetida durante sua separação amorosa: "Eu sou insuportável". O grupo sugere à Germana que ela provavelmente tenha sofrido com a separação familiar e que a forma de expressar o seu sofrimento foi gritando, fato que talvez evocasse não querer ser abandonada. Germana associa posteriormente a ligação do seu trabalho, dedicado à proteção infantil na primeira infância, com sua história pessoal. De forma bastante introspectiva, Germana indaga: "talvez o meu trabalho seja uma forma de reparar minha história pessoal".

O grupo reforça a dimensão social e coletiva do que acontecia com as crianças nascidas na década de 1960 na França. Os participantes evocam suas lembranças, e o senso comum da época, segundo o qual os pais deixavam o bebê chorar. Isso consistia em uma espécie de norma para educá-los desde a primeira infância. Germana dirá, mais tarde, que essa contextualização foi importante para ela pensar que isso não aconteceu só com ela e, assim, entender sua experiência em um contexto social. Essa reflexão parecia trazer para Germana a possibilidade de lançar um outro olhar sobre seu próprio sofrimento. A discussão com o grupo lhe dava um suporte para operar certo distanciamento em relação à sua dor, de forma a sair do isolamento do ressentimento, da solidão simbolizada no início do grupo por meio da sua escultura corporal.

A construção da árvore genealógica é uma atividade realizada em todos os grupos "Romance familiar e trajetória social". Essa atividade pode acontecer no primeiro ou no segundo dia de encontro, em razão da escolha dos coordenadores do grupo. Ela é essencial para que a história de vida seja analisada considerando as heranças sociopsíquicas do indivíduo. Na perspectiva do "Romance Familiar e Trajetória Social", pede-se que a construção da árvore seja feita a partir da geração mais distante, da qual o participante tenha 
conhecimento. Nesse sentido, há pessoas que traçam muitas gerações, enquanto outras mostram pouco conhecimento sobre sua ascendência. No caso de Germana, ela começa pela geração de seus avós. Ela o faz de forma emaranhada e confusa: os avós paternos estão na mesma linha que seus pais. Germana relata que, durante sua infância, a família pouco falou sobre a história do lado paterno. Sabia-se somente que seu pai havia sido abandonado por sua mãe, que foi viver com outro homem.

Os pais de Germana se conheceram e se casaram na ilha de Madagascar, à época, território francês. Nesse ponto, o contexto histórico e político é importante para situar as rupturas sociogeográficas vividas pela família de Germana e que exerceram impacto sobre todos seus membros. Madagascar pertenceu ao governo francês no período de 1897 a 1960.

A família do pai é originária de uma cidade francesa, próxima a Paris, mas se mudou para a ilha. Quanto ao lado materno, sua mãe nasceu em Madagascar, fruto de um casamento entre uma mulher nascida na llha da Reunião, de pele morena, e de um pai francês, branco. Do casamento de seus pais, nasce o irmão mais velho, em Madagascar, e Germana em Paris, em 1957, ano em que sua família chegou à França. Posteriormente, nasceram outros quatro irmãos, embora sua mãe não tivesse desejado ter tantos filhos. Ela se recorda de ter ouvido, aos sete anos, reclamações de sua mãe sobre o número de filhos: "É muito!". Destacamos que seu nascimento coincide com a mudança da família para a capital francesa. Consideramos esse momento como um acontecimentoruptura, pois provocou fortes mudanças e repercussões familiares, selando um período de vida familiar, antes e depois de Madagascar. Essa mudança é simultânea ao seu nascimento e faz Germana sentir certa nostalgia de Madagascar, lugar que nunca conheceu. Ela chega ao mundo em novo momento da família, de retorno à metrópole. Madagascar terá para Germana os contornos das lembranças da mãe, rememoradas como um tempo áureo da família, em contraste com as dificuldades vividas na chegada à metrópole, localidade estrangeira para a mãe.

Germana passou sua vida ouvindo sua mãe reclamar do mau tempo, do frio e da chuva na França, com uma nostalgia de ter perdido o lugar onde nasceu. O maior desejo de sua mãe era viver novamente em Madagascar. No entanto, na época em que Madagascar se tornou independente da França, sua mãe soube que "jamais voltaria a seu país", o que Ihe trazia muita tristeza. Germana faz parte da primeira geração na França, depois da independência: "Se eu tivesse vivido em Madagascar, poderia ter sido diferente".

Segundo Germana, a mudança da família para a metrópole provocou uma perda do status social. Em Madagascar, seu pai era um operário qualificado e tinha uma posição social valorizada. Ser francês e branco possibilitava ocupar um lugar dominante na organização social do país. Chegando à França, seu pai se torna militar de baixa patente, a família perde os bens que tinha em Madagascar. Não 
tinham mais domésticas. Todo dinheiro da família - o salário de militar do pai era empregado na educação dos filhos que estudavam em escolas privadas. Garantir uma boa educação aos filhos era a prioridade de sua mãe, para quem o status social era muito importante. Podemos lançar a hipótese de que o capital escolar dos filhos poderia remediar, ao olhar da mãe, a insuficiência de um capital cultural associado à sua origem madagascarense, recuperando a perda do status social da família depois da chegada à metrópole.

Germana recorda-se que, no colégio, uma professora dizia que ela era "café com leite", referindo-se ao seu tom de pele, fato considerado humilhante para ela, visto que evidencia uma diferença em relação às outras crianças francesas. Lembra que sua família não tinha os mesmos hábitos que as famílias francesas: suas roupas eram muito coloridas, e eles comiam de forma diferente. Eles não conheciam os embutidos, e comiam pratos madagascarenses em casa. Lembramos Bourdieu (1979) para quem os hábitos alimentares evidenciam o pertencimento social familiar, por não estarem submetidos às aprendizagens realizadas e determinadas pelo ambiente escolar, por exemplo. Nesse sentido, as formas de se alimentar, os pratos e as comidas compartilhados no seio de sua família fazem realçar a diferença entre sua família e as famílias francesas. Os hábitos alimentares e vestimentares parecem, assim, revelar o status social da família no contexto francês.

Já adulta, Germana se casa com um diretor de banco, mas ressalta que não estava apaixonada. Ela desejava agradar à sua mãe pela boa posição social do seu marido. Ao selar essa união, Germana parecia se integrar à um status social valorizado no contexto francês. Desse casamento nasceram cinco filhos. Ela não trabalhava, pois o marido exigia que ela se dedicasse à criação dos filhos. Ele trabalhava muito. A cada promoção que recebia, a família o acompanhava, vivendo em várias cidades francesas. Nesse início da constituição da sua família, Germana parece reproduzir a mesma organização de seu núcleo familiar de origem: ela, como sua mãe, não exerce atividade profissional, trabalhando exclusivamente na casa e no cuidado e educação dos filhos, também em grande número. O sustento financeiro da família é responsabilidade do progenitor, assim como o era de seu pai. Também, de forma semelhante, sua família repete a experiência de se deslocar de cidades em decorrência das atividades profissionais do provedor da casa.

O início da trajetória profissional de Germana se dá a partir da aprovação em um concurso público para professora, o que considerava um "passaporte para se divorciar". Trabalhar parece, assim, ter um significado mais profundo para Germana: romper com o modelo familiar que ela vinha reproduzindo. $\mathrm{Na}$ época, ela tinha dois filhos que ainda não haviam terminado o ensino médio. Preparando-se para o momento da separação, ela foi a Paris aos quarenta anos para realizar o concurso e se recorda que, à época, não sabia como andar de metrô. O conjunto da experiência foi difícil, mas conseguiu aprovação e tornouse professora. No entanto, a independência financeira mostrou-se não ser 
suficiente para romper com o casamento. Sua separação se dá apenas em 2005, quatro anos após o falecimento da mãe. Germana diz que não poderia fazê-lo se ela ainda estivesse viva. Não suportaria desapontá-la, pois seria como um descumprimento com uma lealdade familiar relacionada tanto à devoção religiosa quanto ao ideal de ascensão social. Seguindo nossas hipóteses, o falecimento da mãe se configura como um segundo acontecimento-ruptura, que emerge no relato de Germana dentro do grupo, considerando os desdobramentos que esse fato provoca na trama familiar.

O falecimento da mãe também interferiu nas escolhas do pai de Germana. Ele buscou saber mais sobre sua própria história e encontrar sua mãe biológica, pois, enquanto sua esposa era viva, ela o dissuadia de fazê-lo. Sua história é marcada por encobrimentos, que deram origem a rearranjos de situações familiares. Ao ser abandonado por sua mãe, seus avós paternos o assumem como filho, e seu pai biológico exerce o papel de seu irmão. Foi esse arranjo geracional que havia sido apresentado a Germana. Daí a confusão em sua árvore genealógica, quando os avós paternos foram representados na mesma linha que seus pais. As buscas de seu pai por conhecer a mãe biológica levaram-no a descobrir que ela, já muito idosa, faleceu pouco tempo antes de sua esposa. Germana diz sorrindo: "ele poderia tê-la conhecido".

Na história do seu pai, o fato de ele ter sido abandonado por sua mãe, avó de Germana, que fugiu com outro homem, provoca vergonha na família católica da sua esposa. Essa história paterna sofre um duplo acobertamento, sendo negada e encoberta duas vezes. A primeira, mais antiga, quando a avó do pai decide assumi-lo como filho e não neto, junto à família que corrobora com o novo arranjo familiar. A segunda, quando sua esposa, que faz a manutenção desse encobrimento, não concordou que ele buscasse e se aproximasse de sua mãe biológica.

Uma vez que Germana finalizou seu relato, o grupo reflete junto com a participante sobre os acontecimentos que marcaram sua história familiar. Assim, seus membros e as coordenadoras formulam, conjuntamente, hipóteses, de forma a acompanhá-la na análise da sua herança familiar: a) existe uma aliança, criada entre seus pais, sobre as histórias das duas famílias, de forma a esconder suas vergonhas: a vergonha de sua mãe, de seu lugar social associado a Madagascar e a vergonha provocada pela história do pai, abandonado por sua mãe, que foi viver com outro homem - vergonha de ordem social e moral. A coordenadora lembra que a história contada é sempre uma das versões possíveis da história e observa que a mulher que não aparece na árvore genealógica é sua avó. Na produção da árvore genealógica, há a omissão de uma geração, a de seus avós. Há uma colagem entre duas gerações, visto que os bisavós de Germana são apresentados como pais de seu pai (seus avós); b) O status social em Madagascar, proveniente da associação "ser branco", "da metrópole" e "possuir pequeno patrimônio e empregados" dá lugar, na França, a uma família mestiça imigrante -mudança que Ihes faz perder o lugar social valorizado de 
outrora. O tom de pele de sua esposa e filhos na França passam a ser elementos de desvalorização.

Retornando à questão da transmissão, pensamos em Abrahan e Torok (1995). Para esses autores, no psiquismo nada pode ser eliminado completamente, mas terá um traço como enigma, mal-estar ou algo estranho. Para Benghozi (2000), quando há uma transmissão traumática, o traumatismo é a própria marca da transmissão. O fato traumático é objeto de transmissão mesmo que nunca se tenha falado nele no interior da família. As invisibilidades são repetidas de forma inconsciente e, muitas vezes, encerram segredos, não ditos, tudo aquilo que foi escondido. Esses conteúdos são transmitidos sem ser elaborados, podendo provocar traumatismos, inscrições somáticas e transmissões repetitivas. Ao contrário, há uma transmissão adequada quando a geração herdeira se sente livre para transformar sua versão da história, ao passo que, na transmissão congelada, a geração que a recebe sente um impedimento para realizar essa transformação, há uma impossibilidade de elaboração.

Até aquele momento, Germana nunca tinha compreendido que houve uma colagem geracional e que uma mulher havia sido barrada de integrar sua família: sua avó paterna. Após relatar que seu pai sentiu falta de conhecer o destino dela e se deparar com toda tentativa familiar de encobrir sua existência, devido à vergonha, ela pôde verbalizar: "Eu ganhei uma avó". Pôde restabelecer, assim, o vínculo com a imagem da mulher que abandonou seu pai quando bebê. Ela se emociona e diz que pôde reconhecê-la como alguém de sua família. A coordenadora levanta a hipótese de que isso foi possível porque ela lhe deu um lugar que não era vergonhoso, permitindo-Ihe não vê-la unicamente pelo prisma do abandono. O grupo e as coordenadoras insistem que essa versão da história é uma das versões possíveis.

Nesse momento, é sugerido à Germana redesenhar sua árvore genealógica, de forma a dar um lugar a essa avó e ao avô. Essa proposta lhe deixa contente. Germana percebe que ela continuava a esconder a história do seu pai, como fazia sua mãe. No dia seguinte, ela chega cedo ao grupo para refazer sua árvore genealógica, antes do início do novo dia de trabalho. Ela inclui uma outra geração, aquela dos avós paternos.

Uma nova árvore genealógica é colada à parede, e as coordenadoras criam um momento para que Germana apresente o novo desenho. O objetivo era reconhecer esse lugar simbólico dado à avó e ao avô, que não é mais, como no desenho da antiga árvore, o irmão do pai. É importante expô-la ao grupo, que atua como testemunha que legitima o novo entendimento de Germana sobre sua genealogia familiar. Ela afirma: "Nessa nova árvore eu respiro. Na árvore antiga eu estou sufocada. É estranho, quando estamos totalmente imersos. A gente não questiona. Eu vou embora deste grupo com uma avó." 
No último dia de trabalho do grupo, Germana diz estar consciente de ser ainda necessário elaborar sua relação com sua mãe, o sentimento de abandono que ainda está presente no bebê que ela guarda em si.

Levantamos a hipótese de que o trabalho sobre sua história e a história de seu pai lhe permitiram se aproximar de outra maneira da experiência de abandono, da relação com sua avó paterna, que, talvez, tenha-lhe permitido ver de outra maneira sua relação com sua própria mãe. Germana diz que poderá partir em tranquilidade depois de ter participado do grupo. Relata que, em outras participações em grupos como aquele, ela se vinculava excessivamente às pessoas. Chamavam-Ihe de "grude". Ela não podia abandoná-los. Mas, segundo Germana, alguma coisa aconteceu dessa vez. Ela podia deixar o grupo sem dramas. Sua reação nos fez pensar que uma mudança havia sido operada na maneira como ela vive essa problemática do abandono.

\section{CONSIDERAÇÕES FINAIS}

Neste artigo, foi possível ver como o dispositivo "Romance Familiar e Trajetória Social", articulando contribuições teóricas de disciplinas como a psicanálise e a sociologia, nos ajuda a repensar a questão da transmissão e das formas originais que os sujeitos têm de se singularizar.

O conjunto desse dispositivo se refere à importância da narratividade vinculada à história social, familiar e individual. Pode-se dizer que, implicitamente, há uma crítica ao imaginário social contemporâneo, que é muito trabalhado pelo narcisismo social, em que os indivíduos são considerados como os únicos responsáveis pelos seus próprios destinos, como se eles não fossem vinculados a nenhum tecido social, como se fossem desenraizados e os únicos elaboradores de seus próprios projetos.

O dispositivo "Romance Familiar e Trajetória Social" se contrapõe ao modelo do indivíduo autoengendrado e oferece um espaço para que, por meio da narrativa de recortes da sua história de vida, ele passe a se ver como ator de sua própria trajetória. Isso se dá na medida em que a atitude reflexiva exigida por este trabalho convoca cada participante a pensar sobre suas heranças, apropriando-se da sua própria história, construindo significados e agindo sobre ela.

A análise da participação de Germana no grupo "Mudanças: entre rupturas e vínculos" nos possibilitou mostrar como esse referencial teórico-metodológico pode operar, na prática, e como ele pode ser vivenciado por aqueles que dele participam. Pudemos discutir como, na trajetória de vida de Germana, a questão da transmissão transgeracional teve lugar de destaque. Ela é herdeira de uma transmissão velada, considerada desonrosa e vergonhosa na linhagem paterna, sentimento reforçado por sua mãe. Ao realizar o trabalho no grupo, ela pôde se deparar com essa questão e, consequentemente, com a forma como as gerações - do pai e do avô -, encontrando-se misturadas, barravam a existência da avó. 
Germana sentiu necessidade de reordenar as gerações, oferecendo, assim, simbolicamente um outro lugar aos seus ascendentes e também a si mesma. Podemos arriscar dizer que esse ordenamento the possibilitou sair de uma transmissão alienante e ingressar em outra, estruturante. Germana produz uma elaboração genealógica e, ao fazê-lo, reinscreve na ordem geracional mais uma geração. O primeiro desenho da genealogia se encerra com os supostos avós. Ao refazer sua árvore, depois de realizar o trabalho em grupo, constrói outro ordenamento. A geração dos que antes ela considerava como avós paternos passa a ser a de seus bisavós. Esse trabalho produz em Germana outra inscrição na ordem familiar. Ela não só passa a ter bisavós, como se vê agora capaz de transmitir a história não mais pela via do encobrimento, o que, por sua vez, possibilita que outras elaborações sejam construídas.

\section{REFERÊNCIAS}

Abraham, W., \& Torok, M. (1978). A casca e o núcleo. São Paulo, SP: Escuta.

Barus-Michel, J. (2005). Clínica e sentido. In J. Barus-Michel, E. Enriquez, \& A. Levy, Dicionário de psicossociologia. Lisboa, Portugal: Climepsi.

Benghozi, P. (2000). Traumatismos precoces da criança e transmissão genealógica em situação de crises e catástofres humanitárias: Desmalhar e remalhar continentes genealógicos familiares e comunitários. In O. R. Correa, (Ed.). Os avatares da transmissão psíquica geracional. São Paulo, SP: Escuta.

Bourdieu, P. (1979). La distinction, critique sociale du jugement. Paris, França : Ed. de minuit.

Carreteiro, T. C. O. C. (2001a). Psicossociologia em exame. In Machado, M.N.D.M., et al Psicossociologia: Análise social e intervenção. Belo Horizonte, MG: Autêntica Editora.

Carreteiro, T. C. O. C. (2001b). Vinculações entre romance familiar e trajetória social. In FéresCarneiro (Ed.). Casamento e família: Do social à clínica. Rio de Janeiro, RJ: NAU.

Carreteiro, T. C. O. C. (2005). Corpo e contemporaneidade. Psicologia em Revista, 17(11), 62-76.

Corcuff, P. (1993). Pierre Bourdieu avec Löic Wacquant; réponses. Pour une anthropologie reflexive. Revue française de sociologie, 34(2), 293-296,

Fères-Carneiro, T., \& Magalhães, S. A. (2005). Conquistando a herança: Sobre o papel da transmissão psíquica familiar no processo de subjetivação. In Fères-Carneiro (org.). Família e Casal: Efeitos da contemporaneidade. Rio de Janeiro, RJ: EDPUC-Rio/Loyola.

Figueiredo, L.C. (1993). Fala e acontecimento em análise. Percurso, 11(2), 45-50.

Freud, S. (1905). Três ensaios sobre a teoria da sexualidade. In S. Freud, (1901- 1905). Obras Completas. São Paulo, SP: Companhia das Letras.

Freud, S. (1909). Romances familiares. In S. Freud, Edição standard brasileira das obras psicológicas completas de Sigmund Freud. Rio de Janeiro, RJ: Imago.

Freud, S. (1913). Totem e Tabu. In S. Freud, Obras Completas (1912-1914, Vol. 11). São Paulo, SP: Companhia das Letras.

Freud, S. (1914). Introdução ao narcisismo. In S. Freud, Obras Completas (1914-1916). São Paulo, SP: Companhia das Letras.

Freud, S. (1921). Psicologia das massas e análise do eu. Ìn S. Freud, Obras Completas (1920- 1923). São Paulo, SP: Companhia das Letras.

Gaulejac, V. (2001a). Psicossociologia e sociologia clínica. In J. N. G. Araújo \& T. C. O. C. Carreteiro Cenários sociais e abordagem clínica. Belo Horizonte, MG: Fumec.

Gaulejac, V. (2001b). A gênese social dos conflitos psíquicos. Transformações no mundo do trabalho, Cronos, 2(1), 109-115.

Gaulejac, V. (2014). A neurose de classe: Trajetória social e conflitos de identidade. São Paulo, SP: Via Lettera.

Legrand, M.L. (1993). L'approche biographique. Paris, França: Ed. Hommes et Groupes

Lhuilier, D. (2011). Filiações teóricas da clínica do trabalho. In P. Bendassolli, \& L. A. Soboll, Clínicas do trabalho: Novas perspectivas para compreensão do trabalho na atualidade. São Paulo SP: Atlas. 
Oliveira, F. L. G. de, \& Darriba, V. A. (2015). Sobre a importância da transmissão parental do desejo para a psicanálise a partir de um caso de obesidade infantil. Estilos da Clínica, 20(2), 265278.

Scherer, A. D., More, C. L. O. O., \& Coradini, A. O. (2017). Obesidade, família e transgeracionalidade: Uma revisão integrativa da literatura. Nova perspectiva sistêmica, 26(58), 17-37.

\section{CONFLITOS DE INTERESSES}

Não há conflitos de interesse.

\section{SOBRE AS AUTORAS}

Teresa Cristina Carreteiro é psicóloga, mestre e doutora em Psicologia Social Clínica pela Université de Paris. Trabalha na linha de pesquisa Psicossociologia Clínica, particularmente História de Vida e recebe financiamento de pesquisa do CNPq.

E-mail: carreteiro.teresa@gmail.com

(2) https://orcid.org/0000-0001-5657-0043

Ana Massa é psicóloga, mestre em Sociologia pela Université de Paris, doutora em Psicologia pela Universidade Federal Fluminense e em Sociologia pela Université de Paris. Realiza estágio de pósdoutorado na ENSP - Fiocruz com financiamento do Programa Inova. É professora colaboradora da Fundação Dom Cabral. Trabalha na linha de pesquisa Psicossociologia Clínica, particularmente no tema da História de Vida.

E-mail: anamassa@hotmail.com

(2) https://orcid.org/0000-0002-7467-4572

Luciana da Silva Rodriguez é psicóloga, mestre e doutora em Psicologia pela Universidade Federal Fluminense. É professora da Universidade Machado de Assis. Trabalha na linha de pesquisa Psicossociologia Clínica, particularmente no tema da História de Vida.

E-mail: lu83rodriguez@gmail.com

(2) https://orcid.org/0000-0001-6250-6806 